\author{
Artículo \\ El orden como mito y \\ convención. \\ Melva Loran Camacho Correa \\ basilio_juggernaut@yahoo.es \\ DGESPE-SEP
}

DOI: https://doi.org/10.38128/cienciayfilosofa.v1i01.5

\title{
Resumen.
}

Se contribuye a la discusión en torno a los límites del Estado nación respecto al derecho convencional a partir de una crítica a la violencia fundadora de orden, resaltando los contrastes que hay en el proceso de un mercado global que influye en los estados nacionales.

Palabras claves: Estado, Mito, Convención, Derecho, Expiación.

\begin{abstract}
.
It contributes to the discussion around the limits of the nation state with respect to conventional law based on a critique of founding order violence, highlighting the contrasts that exist in the process of a global market that influences national states.
\end{abstract}

Keywords: State, Myth, Convention, Law, Expiation.

Recibido: 25.7:18

Aceptado: $15.8: 18$

Publicado: 12.12:18 


\section{Violencia Mítica}

Lo que se ha denominado violencia mítica parece hallarse en los estratos más hondos de la conducta humana y su correspondencia con un orden evolutivo que recuerda en todo momento la fragilidad de la ley y del derecho o lo que es lo mismo al propio orden del Estado.

Hay que admitir que ha habido una serie de filósofos que han tratado el problema de la violencia mítica para describir la oposición orden-violencia. Benjamin, Calasso y Girard son algunos de los principales filósofos que refieren esta oposición desde diferentes posturas.

Para Girard (1995: 76) la libertad de un orden dado es resultado de la violencia domesticada. Esta afirmación se puede rastrear en la transición del régimen del rito al régimen del mito o bien en la transición de la expiación a la narración. "El orden del sacrificio humano de la víctima cautiva o propiciatoria al sacrificio de animales: chivo expiatorio, bueyes, cerdos, etc., tiene que purificar a la violencia (la mala sangre en sangre buena y purificada) para que el orden se cohesione, para que encadene a la violencia."

El ejemplo más paradigmático lo constituye la tragedia griega de Edipo. La mala violencia que llega a desatar Edipo en la comunidad tiene que ser desterrada; tiene que ser señalada la víctima propiciatoria con el fin de encadenar la violencia individual que brota de la comunidad. La labor de Girard consiste en reconstruir el orden de la violencia mítica desde el sacrificio: desde la expiación hasta el sistema de justicia moderno, reconstruir, el régimen de la expiación y de los mitos fundacionales que llegan hasta el psicoanálisis. Su tesis principal consiste de que un orden en cuanto tal está fundado en una violencia fundadora que polariza lo sagrado y lo impuro.

La violencia sólo es sagrada si se logra este cometido: hacer unánime su purificación. No porque el fundamento de un orden corresponda a un ideal humano sino porque lo humano o más exactamente como lo entendían los romanos, "el homo sacer constituye la ambigüedad de ser un animal cruento que purifica en la violencia su sacralidad instituyendo un orden que la aleje (Agamben, 1995: 52), o en el mejor de los casos, que la violencia quede encadenada en instituciones de violencia legítima, de lo contrario, la violencia volverá a poner en crisis al orden instaurado, purificado: el 
lado sagrado de la violencia, el juridizado por la ley tiene el cometido de alejar a los pendencieros de la sociedad. Sólo la institución de la violencia es exclusiva de un poder secular que no permite la venganza porque es el supremo poder de expiación.

Para Calasso (2000: 144) la transición del régimen de la expiación al régimen del mito se da a partir de lo que llama sustitución. "El origen de la sustitución no es la facultad de dar nombres y sustituirlos por las cosas “(...) sino en aquella, irreductible y englobadora de formar imágenes mentales; entidades invisibles, ocasionales, no permanentes, estados de conciencia que se superponen a lo que se percibe, o también lo sustituye, borrándolo (...) es entonces cualquier acto llevado a la conciencia de dicho proceso.”

Lo que ha acontecido en la cultura es un movimiento de sustitución que no es precisamente el tránsito de un estadio a otro sino la suplantación de un orden por otro, de una legitimidad por otra, porque la misteriosa fuerza de la legitimidad se encierra en sí misma.

El circulo vicioso: la legitimidad es la única fuerza que asegura la duración de un gobierno; pero para que un gobierno llegue a ser legitimo es necesario que lleve tiempo durando. (...) La naturaleza intima de los principios de legitimación es la facultad de exorcizar el miedo." (Calasso, 2000: 59)

Cada forma de suplantación es rompimiento de un ciclo, de un orden cíclico por otra forma legítima de orden que justifica ese rompimiento y asegura la exorcización del miedo a la muerte violenta. Calasso trata de asegurar esta tesis introduciendo el relato de la ruina de Kasch: hubo un tiempo en donde el orden de la comunidad dependía y se correspondía con el movimiento de los astros que marcaban la muerte del rey. No obstante, el relato da testimonio de la expiación frustrada del rey mediante la sustitución de la palabra. Con la muerte de los sacerdotes el orden dependiente del movimiento de los astros sucumbe el régimen de la expiación sustituido por el orden que dan las palabras. El fin del orden de la expiación cruenta (cicloidia sangrienta) a la instauración legitimadora del orden del mito evoca el origen de una violencia fundadora instalada en el recuerdo que portan los mitos de este cambio de régimen.

En su fondo esotérico, el sacrificio sólo pudo ceder al relato, que lo vence en la ordalía. El relato es lo esotérico, el secreto del secreto, enseña a vivir fuera del 
ciclo, en la suspensión hachisiana de la palabra. Para que el relato consiga suplantar el sacrifico cruento, debe contener en sí algo no menos poderoso que el soma. (Calasso, 2000: 132)

Al reino de la palabra después del de la sangre, asegura Calasso, la expiación del soma es sustituida por el cuerpo de las palabras, de las figuras que forman las palabras, instaurando con ello un orden que ya no es cruento sino fabulado:

Es un reino que no mata según el rito, sino que evoca la muerte a través de un desorden que sobreviene rápido, indomable. Las palabras de Far-li-mas sustituye el sacrificio: como el sacrificio tiene el poder de hacerse obedecer, pero no tiene el poder de establecer los tiempos del ciclo. Ahora el tiempo es la oscilación pendular entre un fluir vacío, desprovisto de apoyos, y la suspensión de la droga de las palabras. (Calasso, 2000: 136)

Según este tipo de movimiento de sustitución, según esta sabiduría, nos dice que a pesar de que el nuevo orden (el de la narración) ya no es cruento, a pesar de que se ha expulsado a la expiación, no por ello ésta ha desaparecido, más bien se ha instalado en otras formas jurídicas que censuran su continuidad esotérica. Con el mito lo exotérico de la narración conforma un nuevo orden dominado por la fabulación, donde el tiempo se subordina a la narración, y en vez del ciclo esotérico de los astros ahora el nuevo orden está dominado bajo otras formas arquetípicas que atrapa la fabulación para narrar el orden del progreso que instaura el imperio del mito.

Sucintamente, el mito no sólo llegó a instalarse fuera del ciclo de la expiación como una forma de asimilación de un orden de sustitución no cruenta y justificadora de ese mismo orden como sostiene Calasso, sino que el mito encierra el poder del progreso que dota a la totalidad de su movimiento. El poder del mito tiene que ver con las formas narrativas y simbólicas que instauran una temporalidad progresista que supera infinitamente los estrechos límites del régimen de la expiación. El desplazamiento del régimen de la expiación por el régimen de lo imaginario no sólo estriba en la justificación de un nuevo orden sino en la domesticación del devenir porque está latente la prohibición, el tabú, la sangra y la fagia.

La violencia mítica también es tratada por W. Benjamin dentro de una concepción crítica de la violencia. 
La violencia mítica en su forma ejemplar es una simple manifestación de los dioses. Tal violencia no constituye un medio para sus fines, es apenas una manifestación de su voluntad, y sobre todo, manifestación de su ser. La leyenda de Níobe constituye un ejemplo evidente de ello. Podría parecer que la acción de Apolo y Artemisa es solo un castigo. Pero su violencia instituye más bien un derecho que no castiga por infracción de un derecho existente. El orgullo de Níobe atrae sobre sí la desventura, no porque ofenda el derecho, sino porque desafía al destino a una lucha de la cual éste sale necesariamente victorioso y sólo mediante la victoria, en todo caso engendra un derecho." (Benjami, 1982: 41)

Benjamin también es partidario de la idea según la cual la fundación del orden está constituida por la violencia fundadora y conservadora de derecho. Hasta aquí se asemeja a Girard, sólo introduce una oposición mítica de violencia: la violencia divina destructora de derecho. Mientras que en Girard la violencia tienen que encontrar su oposición orden/desorden para purificarse y eliminar ambigüedades, en Benjamin la violencia de un orden es algo ya antinatural.

Así, la crítica a la violencia que funda al derecho y lo conserva, es la crítica contra el derecho entendido como Estado, es la crítica que opera en la historia de los estados y en especial al Estado moderno que se funda en el derecho. Dice Benjamin:

Así como en todos los campos Dios se opone al mito, de igual modo a la violencia mítica se opone la divina. La violencia divina constituye en constituye en todos los puntos la antítesis de la violencia mítica. Si la violencia funda al derecho, lo divino lo destruye: si aquella establece límites y confines, ésta destruye sus límites; si la violencia mítica culpa y castiga, la divina exculpa; si aquella es tonante, esta es fulminante, si aquella es sangrienta, esta es letal sin derramar sangre. A la leyenda de Níobe se le puede oponer, como ejemplo de esta violencia, el juicio final de Dios sobre la tribu de Korah. (1982:42)

Historia y destino es la mayor oposición que podemos encontrar en Benjamin porque no se trata de encontrar en los mitos fundacionales una arqueología del progreso entendida como sustitución como la presenta Calasso, sino de advertir el destino del derecho.

El derecho ha gozado de una reputación en los últimos doscientos años para constituir a la sociedad, se considera, en términos de eficacia, una de las mayores ventajas para la cultura porque limita a la violencia, aunque el mismo derecho sea una violencia conservadora. 
La paradoja que presenta el derecho, entendido como Estado, es que en su interior existen derechos latentes que lo desarticulan en cuanto alcanzan la condición de violencia fundadora.

Maquiavelo (2009: 12) ya había anticipado esta fatalidad de la violencia entendía como poder constituyente o principatibus. No obstante, lo que introduce Benjamin es que la condición de crear orden por medio de la violencia, no solo no escapa al Estado moderno sino que su destino es la disolución. El proceso de la historia es a la vez el proceso de la disolución del Estado por la violencia mítica. Un proceso cuyo destino sería el fin da la prehistoria en el sentido como lo entendía Marx (2010: 7), solo que la violencia divina es la que realiza este secreto cometido diariamente.

Toda violencia mítica que funda el derecho, la violencia administrada, que la sirve, La violencia divina que es enseña y sello, nunca instrumento de sacra ejecución es la violencia que gobierna. (1982: 49)

Lo que nos enseña Benjamin con la crítica a la violencia no es otra cosa es la condición violenta del conocimiento de la acción que hasta ahora ha estado motivada por la violencia fundadora y conservadora de derecho que conocemos como Estado. La oposición entre violencia mítica y violencia divina es un recurso dialéctico para reconocer que el sistema de derecho lleva en sí la condición de la violencia administrada para unos seres cruentos en un Estado cruento cuyo destino es su propia disolución. Lo sagrado condiciona ese proceso o filosofía de la historia como lo llama Benjamin. En este sentido, las teorías defensoras del Estado no dan cuenta del destino del derecho, al contrario lo siguen fabulando, por ejemplo el comunitarismo.

Una conciencia simbólica es más profunda que una dialógica para describir la condición violenta del conocimiento de la acción como lo deja ver especialmente Benjamin.

Así que proponemos para el siguiente parágrafo describir el desarrollo histórico del Estado nación visto como una consecución necesaria del capital que condiciona la historia y el destino del Estado nación. Veamos si la tesis de Benjamin aún se sigue sosteniendo. Por lo pronto implicaríamos lo siguiente. Las fuerzas soterradas del mito (Cassier, 1974: 350) que tanto temor causaron y que pusieron en riesgo al Estado racional positivo a mediados del siglo XX hoy no representan lo mismo. 
El estudio sobre la violencia mítica ha descubierto en una serie de paradojas la eliminación de ambigüedades que representaban para la época pasada. La importancia de las fuerzas imaginantes ha ido creciendo en valor en cuanto que describen las fases de la cultura y su estatus. Los ejemplos que hemos puesto como son el sistema de justicia, el progreso de la cultura de la no violencia y la crítica a la violencia en la fundación de derecho le dan un lugar apropiado a las fuerzas imaginantes que el logocentrismo (Horkheimer, 2007: 107) entendido como discurso racional le había arrebatado en el proceso de formación del Estado nacional y su subsecuente desenvolvimiento.

\section{Estado-Mercado.}

Logos y mito se han opuesto a lo largo de los últimos doscientos cincuenta años de historia basada en estados nacionales. No obstante, hemos tratado de probar que esta oposición es aparente. No solo estamos de acuerdo con Cassier (Cassier, 1974: 21) en el sentido de que no se excluye del todo al mito sino que además ahora vive instalado en forma de pluralidad política.

De acuerdo con esto, hemos implicado, a partir de Benjamín, que la crítica a la violencia no es dependiente de un discurso racional, sino que las fuerzas imaginantes del mito describen la fundación y conservación de la violencia del orden como condición violenta del conocimiento de la acción. Esta última tesis trasladada a la oposición Estado- Mercado nos permitirá deducir hacía dónde se conduce el Estado-nación, como un orden más en la historia, que ha conservado una ordalía para repetirse como orden, es decir: que tiene la capacidad de reconstituirse con las mismas condiciones que lo habían disuelto.

Nos queda por tanto, describir cómo las fuerzas del mercado han moldeado al propio Estado a su imagen y semejanza en donde la nación sólo ha sido una determinación más que configura el capital en su proceso de desarrollo. Karatani $(2010,19)$ lo expone en el siguiente cuadro: 


\begin{tabular}{|l|l|l|l|l|l|}
\hline & $1750-1810$ & $1810-1870$ & $1870-1930$ & $1930-1990$ & $1990-$ \\
\hline $\begin{array}{l}\text { Capital } \\
\text { mundial }\end{array}$ & Mercantilismo & Liberalismo & Imperialismo & $\begin{array}{l}\text { Capitalismo } \\
\text { tardío }\end{array}$ & Neoimperialismo \\
\hline Hegemonía & & Inglaterra & & Estados unidos & \\
\hline $\begin{array}{l}\text { Política } \\
\text { económica }\end{array}$ & Imperialista & Liberalista & Imperialista & Liberalista & Imperialista \\
\hline Capital & $\begin{array}{l}\text { Capital } \\
\text { mercantil } \\
\text { industria lanera }\end{array}$ & $\begin{array}{l}\text { Capital } \\
\text { industrial } \\
\text { Industria } \\
\text { algodón }\end{array}$ & $\begin{array}{l}\text { Capital } \\
\text { financiero } \\
\text { industria } \\
\text { pesada }\end{array}$ & $\begin{array}{l}\text { Monopolio } \\
\text { estatal }\end{array}$ & $\begin{array}{l}\text { Muntinacional } \\
\text { información }\end{array}$ \\
\hline $\begin{array}{l}\text { Mercado } \\
\text { mundial }\end{array}$ & Industria lanera & $\begin{array}{l}\text { Industria } \\
\text { algodonera }\end{array}$ & $\begin{array}{l}\text { Industria } \\
\text { pesada }\end{array}$ & $\begin{array}{l}\text { Bienes } \\
\text { duraderos }\end{array}$ & Información \\
\hline Estado & $\begin{array}{l}\text { Monarquía } \\
\text { absoluta }\end{array}$ & Estado-Nación & Imperialista & $\begin{array}{l}\text { Estado } \\
\text { benefactor }\end{array}$ & $\begin{array}{l}\text { Regionalista } \\
\text { (Tratados } \\
\text { regionales) }\end{array}$ \\
\hline
\end{tabular}

El capital desde su inicio como sistema económico ha tendido a la globalidad es decir, a desarrollar un Mercado Mundial. El desarrollo del capital ha culminado en ser una fuerza preponderante que condiciona a los estados para su expansión; esto último lo podemos ver reflejado en los estados a lo largo de las distintas metamorfosis por las que han atravesado estos estados a lo largo de los últimos doscientos cincuenta años: desde el Estado absolutista, pasando por el Estado nacional liberal hasta el Estado de Derecho regional.

Sin embargo, no siempre esta tesis fue aceptada, porque en el supuesto de admitirla se asumían unas implicaciones peligrosas tales como: hay de fondo una filosofía de la historia en la que domina una fuerza como lo es el capital que domina las mentes de los hombres, su voluntad y su destino. Una tesis muy metafísica comparada con el ideal de Estado racional positivo que establece comunicación e intercambio con otros estados igualmente constituidos. Los defensores del Estado racional devenido en Estado de Derecho como lo es Kelsen se opusieron desde el inicio a la tesis del Mercado sobre el Estado, lo paradójico es también Kelsen desarrolla una filosofía de la historia en la que culmina el Estado nación cuya superación es una red jurídica internacional: un solo Estado de Derecho que alcanza las magnitudes del Mercado. Veamos esta propuesta.

Kelsen, (2007: 157) en su obra más significativa como lo es Teoría pura de derecho establece una oposición distintiva en cuanto al derecho internacional se refiere: "El derecho internacional convencional y el derecho internacional general de origen consuetudinario, no 
son sistemas coordinados, ya que el primero tiene su fundamento en una norma del segundo, y le está, por lo tanto, subordinado (...) es por lo tanto importante no confundir el punto de vista histórico con el normativo."

Para Kelsen los estados nacionales históricamente se han desarrollado en la historia en la misma proporción de cómo han desplegado sus fuerzas para limitar a otros estados. Kelsen parte de una visión antropomorfa de Estado que ha evolucionado en el intercambio económico y cultural cuyo resultado es un estatus en el que los estados nacionales más poderosos han establecido una serie de pautas y conductas que rigen su influencia sobre los demás sin que predomine un sistema normativo valido para el resto de las naciones.

El derecho internacional conoce dos sanciones específicas, la guerra y las represalias, pero se encuentra en un estado primitivo, superado desde hace tiempo por órdenes jurídicos nacionales. (Kelsen, 2007: 158)

La preponderancia de un derecho internacional dominado por la historia de las guerras no establece un ideal de justicia regulativa sino la imposición por la fuerza de represalias y sanciones que limitan el desarrollo de las naciones más débiles o pacíficas. Sin embargo, las bases consuetudinarias del derecho internacional no son la única traba, el dogma de la soberanía de Estado, representa un obstáculo subjetivo para el desarrollo de un sistema internacional de mayor funcionalidad y progreso.

El dogma de la soberanía del Estado y la primacía del orden jurídico nacional que es su consecuencia se vinculan a la concepción subjetivista tiende al solipsismo, que coloca al individuo, al "yo" en el centro del mundo y ve en este mundo un objeto de la voluntad y de la representación del "yo" (2007: 165)

Para superar esta trabazón histórica que ha producido el Estado nación, Kelsen vuelve al postulado de Rousseau: "de la filosofía individualista, según el cual por su naturaleza el hombre es libre y no puede ser obligado sino por su propia voluntad. La necesidad de un reconocimiento del derecho nacional no era extraída del derecho positivo, sino de la naturaleza del hombre, o más exactamente de una filosofía de los valores." (2007: 157) Este postulado, implica un cambio de paradigma de derecho: de una teoría emanacionista en la que descansa el dogma soberanista de derecho hacia una teoría 
axiológica en la que se subordinar los valores jurídicos, de modo que es preciso que el derecho internacional dicte la autorización de crear normas jurídicas hacia los estados.

La teoría pura de derecho quita al Estado el carácter absoluto que el dogma de la soberanía le confiere. Lo relativiza al considerarlo como un estado intermedio en la serie de formas jurídicas que va de la comunidad universal del derecho internacional, a las diversas comunidades jurídicas subordinadas al Estado. (2007: 174)

Menos de cuarenta y cinco años han pasado desde que Kelsen proponía un solo sistema jurídico internacional convencional, basado por su puesto en la convención de Rousseau, de modo que no podemos decir que este ideal ha fracasado. Lo que podemos decir es que Kelsen vuelve a reproducir un ideal de racionalidad que abstrae al conflicto real de la violencia. Asume la creación de una comunidad internacional que rija a las comunidades jurídicas dependientes hasta ahora del Estado e incluso a los estados regionales como se comprenden hoy en el marco de los tratados económicos. Aunque es una propuesta meramente formal se ajusta sin embargo al esquema que nos propone Karatani para comprender el desarrollo de capital hacia una conformación de mercado mundial donde los estados nacionales han sufrido una serie de transformaciones en función del flujo de mercancías y el intercambio cultural. Por tanto, podemos decir que la propuesta de Kelsen para superar al Estado nación solo se ajusta a un concreto histórico desarrollado como lo es el Mercado Mundial que se ha visto obstaculizado por las dos trabas que el jurista señala. Hasta aquí sería pertinente decir que el orden del Estado nación languidece en el tiempo.

Así como los estados anteriores menguaron hasta su disolución cuando fueron sustituidos por el Estado moderno motivado una racionalidad imperecedera que lucha contra la violencia del mito, así también parece que el Estado nacional está cediendo paso a la conformación de un Mercado Mundial que articulará un sistema jurídico internacional en el que desaparecerá el centro de gravedad del sistema jurídico basado en la nacionalidad, soberanía e independencia como principios de orden de Estado.

Sin embargo, queremos destacar que esta confirmación no se deduce de Kelsen sino de la evolución del Mercado Mundial y su impacto en el actual estatus que guardan los estados nacionales con mayor influencia en el poder para decidir la nueva cartografía de la 
geopolítica. Una decisionalidad histórica que se verá en las próximas intervenciones militares que desaten una guerra que disuelva a las naciones en función de un sistema jurídico internacional basado en regiones económicas.

Karatani (2010: 11 ss) nos puede ayudar a despejar este problema. Al examinar el concepto de repetición en Marx, deduce Karatani que la ciencia en Marx consistía en trabajar con predicciones, partiendo de ciclos de crisis cortos, "bandas cortas de diez años que debían predecir la siguiente revolución social, lo cual no sucedió como Marx esperaba a principios de la década de los años 50's del siglo XIX, más bien lo que ocurrió fue que se descubrió un periodo de revolución política seguido de un periodo de revolución de las multitudes que oscila entre seis denarios o 60 años, mientras que las bandas largas de revolución política abarcan lo doble. La tabla que nosotros hemos sintetizado aclara el sentido de repetición al que nos estamos refiriendo.

\begin{tabular}{|c|c|c|c|c|}
\hline $\begin{array}{l}\text { Inicia } \\
\text { medición de } \\
\text { Marx }\end{array}$ & 1789 & $\begin{array}{l}\text { Revolución } \\
\text { francesa }\end{array}$ & $\begin{array}{l}\text { Revolución } \\
\text { política }\end{array}$ & $\begin{array}{l}\text { Kant, La paz } \\
\text { perpetua }\end{array}$ \\
\hline 30 años & 1848 & $\begin{array}{ll}\text { Inicia } & \text { la } \\
\text { emancipación } & \\
\text { sindical } & \text { en } \\
\text { Europa } & \end{array}$ & $\begin{array}{l}\text { Revolución de } \\
\text { masas en Europa }\end{array}$ & \\
\hline 120 años & 1917 & $\begin{array}{l}\text { Revolución rusa y } \\
\text { mexicana }\end{array}$ & $\begin{array}{l}\text { Revolución } \\
\text { política }\end{array}$ & $\begin{array}{l}\text { Liga de las } \\
\text { naciones }\end{array}$ \\
\hline 30 años & 1968 & $\begin{array}{l}\text { Derechos de } \\
\text { minorías en todo } \\
\text { el mundo }\end{array}$ & $\begin{array}{llr}\text { Revolución } & \text { de } \\
\text { masas en } & \text { el } \\
\text { mundo } & & \\
\end{array}$ & \\
\hline 120 años & 2037-40’s & $\begin{array}{l}\text { Pronóstico de } \\
\text { guerra imperial }\end{array}$ & $\begin{array}{l}\text { Revolución } \\
\text { política }\end{array}$ & $\begin{array}{l}\text { Se espera tratado } \\
\text { de pacificación }\end{array}$ \\
\hline
\end{tabular}

Karatani nos presenta un desenvolvimiento de repeticiones que llevan el sello de la inmanencia con la que obra la conformación de un Mercado Mundial y sus consecuencias para el derecho internacional. A diferencia de Kelsen que parte de un supuesto ya desarrollado, Karatani logra captar al conflicto desdoblado en revolución política y revolución de masas, una doble condición del orden del Estado nación en su determinación de violencia. Benjamin (1982: 35) ya había anticipado este desdoblamiento de violencia del orden del Estado nación al oponer la revolución política contra la revolución proletaria. La primera funda y conserva al derecho mientras que la segunda destruye al Estado 
entendido como sistema jurídico. Esta oposición es decisiva en Bejamin porque revela la naturaleza del propio derecho que se funda en la violencia. Una determinación de orden que se encuentra completamente ausente en Kelsen que se apoya solo en los avances del Estado de Derecho nacional. La debilidad de los argumentos de Kelsen radica en que: quiere elevar a norma de certeza el progreso del Estado de Derecho a Derecho internacional sin la mediación con las cosas.

En Fuerza de Ley, Derrida (1997: 121) hace una reinterpretación a la Critica de la violencia de Benjami y llama la atención cuando dice que: "Los conflictos entre los hombres pasan entonces por las cosas y es tan solo en esta relación, la más realista, la más $<<$ cosista $>>$ donde se abre el dominio de los medios puros, es decir el dominio de la técnica." Decir que la revolución política funda y conserva al derecho significa que hubo una mediación en donde las cosas atraviesan al conflicto y se plasman en un sistema jurídico que guarda ese orden. Esta metodología o este método de integración de poder no es exclusivo del mercado mundial sino que solo ahora se hace evidente tras el proceso de expansión del capital global que ha moldeado o metamorfoseado al Estado de derecho.

Por tanto, la tesis según la cual el Mercado condiciona al Estado sólo es válida desde las revoluciones políticas en las que se diseñan las nuevas superestructuras juríco-política. Así que el Estado nación solo sería una configuración más del Mercado cuyo límite es el propio desarrollo de un Mercado Mundial que prescinde de él.

Esta tesis resuelve parcialmente aquella afirmación según la cual el Estado languidece en el tiempo. Ya que habíamos dicho que la ordalía del Estado nacional basada en la convención consiste en que el este Estado se someterse a prueba ante la excepcionalidad de las crisis políticas.

Es tan eficaz el ideal de convención que el propio Kelsen tiene que decidirse por ella para superar las trabas del derecho internacional consuetudinario y del Estado nacional. No obstante, hay que decir que nos encontramos ante una oposición que se da entre método de integración realizado por el Mercado y la racionalidad del Estado, pues ¿hasta a dónde la expansión del Mercado diseña la superestructura jurídico-política y en qué grado se ve menguado el Estado?

La respuesta que da Karatani es inmanente al Mercado y tiene que ver con la guerra; mientras que la respuesta que da Benjamin tiene que ver con la condición violenta del 
conocimiento de la acción. Al respecto, Karatani se ubica en la disolución parcial y total del Estado anterior, mientras que Benjamin plantea una condición antropológica de la violencia. Para hacer operante esta oposición, diremos que Mercado y Estado son los gemelos fundacionales que en el devenir de la historia arrojaran un nuevo orden que desconocemos. Esta oposición representan la superación de lo que podemos denominar norma de certeza del orden: libertad y exacción inequivalente de las relaciones sociales que atraviesan las cosas, desde las relaciones más concretas hasta los tratados comerciales y culturales que se dan entre las naciones.

Por eso podemos deducir que la condición violenta del conocimiento de la acción consiste precisamente en diagnosticar el siguiente movimiento en el que se verán obstaculizados los derechos y el flujo de las mercancías. Sorprendentemente Karatani percibe este movimiento como un movimiento guiado por el Mercado, aunque hay que decirlo: es intuido por Benjamin para describir la naturaleza de las revoluciones políticas de las que prescinden los juristas como Kelsen.

Así, la oposición entre mercado/Estado aparece como violencia fundadora de derecho/violencia conservadora de derecho, que no prescinden de la norma de certeza del orden: libertad e inequivalencia en las relaciones sociales. Simplemente no se puede superar esta norma de certeza, este canon del orden. Tendría que haber una revolución que disuelva al Estado, una revolución proletaria -como decía Benjamin siguiendo a Marx- que de inicio a un nuevo conocimiento de la acción sin violencia. Un nuevo periodo de Justicia guiado por el destino de la violencia sagrada. Sin embargo, esto no es posible hasta que el Mercado no cumpla su proceso de expansión y hasta que no haya desaparecido el Estado nación. Derecho e Historia van cumpliendo su cometido en un mismo destino cuando el derecho fundado en la violencia desaparezca y la acción no sea condicionada por violencia. Lo que hemos denominado la norma de certeza del orden: libertad e inequivalencia en las relaciones sociales constituye la condición violenta del conocimiento de la acción que es imprescindible al Derecho en sus diferentes ordenes: internacional y estatal.

Esta reinterpretación de Benjamin hace momentánea y pasajera a la propuesta de Kelsen para superar al Estado nación por medio de un derecho internacional convencional. Es muy probable que el siguiente periodo de guerra tenga como resultado un periodo de pacificaciones que supere al derecho internacional consuetudinario mediante un derecho 
que tal vez sea convencional, sin embargo, es dudoso decir que la correlación entre los estados supere la dependencia económica que es una necesidad para las fuerzas del Mercado. De modo que no deja de ser una robinsonada el ideal de individuos iguales- estados iguales. Simplemente esto es imposible: uno de los gemelos tendrá que matar al otro para fundar una nueva norma de certeza.

Por tanto, nuestra tesis que hemos demostrados consiste en que el análisis del Estado nación solo puede ser planteado en términos de mito y convención. El Estado racional positivo resultó ser sospechosos para la propia tradición posliberal y multiculturalista, pese a que no advierte del obrar de la norma de certeza del orden. En cambio, las fuerzas imaginantes han ido a lo más profundo de la condición cruenta que define lo humano para demostrar la inmanencia de la condición violenta del conocimiento de la acción para fundar y conservar al orden de derecho. Lo que queremos decir es que con el surgimiento de las fuerzas imaginantes se ha establecido nuevos puntos epistémicos que eliminan las ambigüedades que surgen si alguna de las fuerzas impera sobre la otra. Esta advertencia ya se encontraba en Cassier, sólo que hacía falta maduración, que Bachelard (2016: 56) le propició para que se estableciera una dialéctica de oposiciones cotidianas como las que hemos presentado aquí para tratar las paradojas que surgen entre realidad y ensoñación.

En consecuencia, mito y convención representan las fuerzas imaginantes y las fuerzas razonantes respectivamente en las que se analizar el progreso cultural logrado hasta ahora por el Estado nación. Pero también cabe el análisis crítico del límite y la disolución del Estado nacional propiciado por una fuerza englobadora como lo es la del Mercado.

\section{Conclusiones.}

La implicación más importantes tiene que ver con la oposición entre violenciaconvención. Hemos visto con Calasso una evolución del progreso de legitimación del régimen del rito al régimen del mito. Con la aparición de la convención se da un nuevo giro de legitimación donde la violencia ya es diagnosticada, lo mismo que su narración. Tafoya lo dice en los siguientes términos: 
La simbólica del salvaje en Rousseau contiene una estructura mítica a través de un relato postulado como historia verdadera pos las siguientes razones: 1) porque remite a un origen sobre-natural (natural artificialmente constituido); 2) porque la repetición permite su objetivación en el presente, es decir, porque la invariabilidad de su realización comprueba su existencia; y 3) por el hecho de que se trasmite a través de una tradición oral y escrita: tanto la narrativa escrita que representa un tratado racionalizado sobre la convivencia huma como la narrativa del relato personal. (Tafoya, 2012: 99)

La ensoñación que se crea a partir del supuesto del buen salvaje permite una eufemización que hace posible una abstracción completamente artificial como lo es la convención, lo paradójico como lo señala Tafoya, es que aparece un acuerdo racionalizado y una narrativa personal que limita la personalización de la violencia. Esta legitimidad supera todas las legitimidades anteriores que contenían a la violencia porque la ordalía entendida como capacidad de ponerse a prueba cumple el cometido de la repetición invariable.

Sin duda este es un logro de la razón como ya lo había anticipado la ilustración al decir que habían "establecido los cimientos de la cultura convencidos de que los habían construidos para la eternidad, su posesión era perdurable" (Cassier, 1974: 351) El régimen de la convención con su propia ordalía de legitimación ha propiciado una serie de progresos para el Estado constituido como nación, incluso ha sido candidato propicio para desplazar al derecho internacional consuetudinario como lo propone Kelsen, sin embargo, tiene algo que no convence: la artificialidad, la promesa que hay de fondo y que lleva a languidecer al Estado. Dice Tafoya:

En Rousseau la promesa de una sociedad mejor y de un buen gobierno, solo es posible al evocar un tiempo primordial, donde el salvaje cobre sentido por su situación de libertad. Antes de explicarnos el acto el pueblo elige a su gobernante, es necesario comprender el acto por el cual un pueblo se constituye como sociedad. Una sociedad, constituida como un artificio, se constituye como tal por un acto de convención que antecede a todo. Pero una convención sólo es posible si se postula la necesidad de retroceder a una convención primitiva. (Tafoya, 2012: 99)

El defecto que tiene la convención consiste en su artificiosidad del origen de la promesa que es propiamente la lectura de un Estado nación, es decir su Constitución en el sentido de Norma Suprema que languidece al Estado porque la promesa no se ve realizada 
sino que forma parte de un proceso más global como lo es el del Mercado. Finkielkraut ha desarrollado una crítica contra el cosmopolitismo del Mercado como uno de los principales factores que contribuyen a que el Estado languidezca. El Mercado es un reino mediático de la confusión que hace de la sociedad una sociedad finalmente convertida en adolecente en donde los valores de racionalidad con los que opera el Estado nación para definir al ciudadano están siendo agotados por esta sociedad poliforme llena de migrantes, auge del etnicismo y un consumo voraz que acaba por borrar los puntos de apoyo de una cultura guiada por el pensamiento.

Nación contra nación, los tradicionalistas combaten de libre asociación con la totalidad globalizante, y al modelo rousseauniano de la voluntad general oponen el concepto de inconsciente colectivo. Al ser el hombre la obra de su nación, el producto de su entorno y no al revés, como creían los filósofos de las Luces y sus discípulos republicanos, la humanidad debe declinarse en plural: no es otra cosa que la suma de los particularismos que pueblan la tierra. (Finkielkraut, 2000: 20)

Finkielkraut predice el languidecer del Estado nación que es precisamente una cultura basada y guiada por los sentidos de la vista y el oído. Un sensualismo visual y auditivo borran los puntos de la cultura anterior que tanto defendía Habermas (1973: 72) y Taylor (1993: 25) con su idea de pluralismo dialógico.

En lo que va del siglo XXI se ve confirmada cada vez más la tesis de Finkielkraut sobre las decisiones que toman los Estado en función de sus fronteras como consecuencia de regímenes de gobierno que han permitido que estos puntos de apoyo se borren y que exacerbe un nacionalismo radical.

Podemos decir, que el Mercado Mundial entendido como una red de comunicación que permite el flujo de las mercancías tiene una lógica completamente diferente de la que muestra el Estado nación, es decir que estamos ante la presencia de una inconmensurabilidad de fuerzas y valores en donde el Estado ha sido el más afectado.

Recordemos con Heráclito que todo fluir lleva a la muerte, esto es precisamente lo que ha sucedido en la red de comunicación que ha propiciado el Mercado cuyas fuerzas imaginantes tocan fibras más profundas en la subjetividad individual en cuanto que están 
definiendo las personalidades de los ciudadano y no ciudadanos dentro de un Estado: están borrando la certeza de formación cultural que se atribuía el Estado nación.

Este proceso, apenas ha comenzado, no sabemos si durará menos de cien años, lo que podemos decir, siguiendo a Kelsen es que será un proceso de desplazamiento de la convención hacia un nivel internacional, según las necesidades del nivel de flujo y comunicación de las mercancías para un consumo mundial en tiempo $=0$.

El proceso de desplazamiento que estamos señalando no será pacifico sino que tenderá a una pacificación como consecuencia de una forma de culturalización que ha comenzado las trasnacionales para extender las red de flujo de las mercancías, de modo que de nuevo serán los detonantes los tráficos intrafronterizos los que desaten un proceso de pacificación tras un guerreo entre naciones que limiten la expansión de un capital hibrido, dependiente de un capital financiero internacional igualmente hibrido.

Nos atrevemos a decir esto porque hemos aprendido un conocimiento sumamente valioso como lo es la condición violenta del conocimiento de la acción que Benjamin desinteresadamente regaló a la humanidad. No habrá derecho que sea reconocido, como hasta ahora, por una violencia que no esté atravesada por las cosas, ya que es la que propicia una violencia fundadora y conservadora de derecho.

Esas cosas no serán los espacios y por supuesto las materias primas puesto que el capitalismo anterior ha propiciado una división de trabajo entre Norte y Sur. Más bien seguirá siendo, como diría Marx (2007: 235) una lucha por la repartición de la plusganacia entre los capitales regionales.

No es que tomemos, al final, una postura netamente marxista para decidirnos por una historia de la filosofía sino que el problema de la norma de certeza del orden: libertad e inequivalencia en las relaciones sociales, constituye una paradoja que se hará insoportable en la misma proporción al crecimiento del consumo.

Por un lado el desarrollo de una libertad de (por o posición a una libertad para) sobrecargará todos los sistemas de gestión institucional: estatales y no estatales para cubrir las solicitudes de necesidades correspondientes al consumo; mientras que por el otro lado la inequivalencia inherente al capitalismo en cuanto a las relaciones que de él se desprenden tendrán los efectos en la suspensión de pagos y problemas de liquidez en deudas fundamentalmente estatales vulnerando a los gobiernos. El resto ya lo conocemos como 
crisis, de modo que no podemos decir mucho al respecto pues solo se trata de un desplazamiento del régimen de la convención con la misma situación que la motiva, y que es lo que nosotros hemos denominado la norma de certeza del orden que no cambiará en mucho tiempo.

Así, consideramos que nuestra investigación no conduce hacia una filosofía de la historia, en el sentido de Marx o Benjamin, sino más bien su valor radica en proponer un análisis plausible del Estado nación que vemos languidecer por las fuerzas del Mercado, no perdiendo de vista que el Estado en general ha sido un método de integración política para ampliar el dominio, el poder y la influencia hacia otras entidades con los mismos rasgos, sólo que ahora se realiza desde un Mercado con capacidad de ubicuidad de la que ningún Estado hasta ahora ha logrado por sí mismo, ni siquiera como imperio. En esta propuesta de análisis no hemos demeritado la eficacia que tiene el régimen de la convención en su ordalía de legitimación, por el contrario la hemos afirmado como un triunfo de la autonomía de la razón, lo que sabe hacer la razón ante la crisis, es decir repetirse para instaurar el orden anterior.

Lo paradójico de esta noción de razón instrumental es que solo crea artificialidad sobre los estratos más profundos de la violencia. Aquí queremos llamar la atención para actualizar la tesis de Cassier. Los estados han languidecido porque se construyen sobre una violencia que no es soterrada del todo y que vuelve a resurgir en forma de mito para acabar su obra que es la disolución del Estado.

Edificar la cultura en la apariencia, edificar pura artificialidad se corresponde a lo que enseña el psicoanálisis cuando nuestra personalidad es artificial: mientras nuestros complejos, neurosis, sadomasoquismos y demás fuerzas del subconsciente sigue latente sin ninguna transformación o progreso anímico nada se ha hecho al respecto, surgirá el mismo complejo reptilineo instaurando jerarquías de poder, ritualización, sexualización para definir su identidad.

Por eso en el régimen de la convención sigue habiendo violencia, transgresión y corrupción de ciudadanos, instituciones y leyes. Sigue predominando la condición cruenta de lo humano como en los regímenes del rito y el mito, solo que ahora predomina la artificialidad mas no el ciclo de las estrellas o el hachís de las palabras. Esto último le faltó añadir a Cassier en su obra El mito del Estado para que quedara imborrable. 
Lo que le faltó al análisis de Cassier fue describir la ordalía de legitimación del régimen de la convención para descubrir la artificialidad del régimen de la convención y la abstracción que hace del conflicto que yace latente como violencia mítica. No obstante subrayamos que fue un gran descubrimiento el que hizo Casisier al haber recuperado la parte inconsciente que representa el orden cuando languidece el Estado, la parte irracional de la violencia que yace latente cuando la efectividad del Estado entendida como unidad política, regularidad, legalidad y legitimidad se hace evanescente y aparecen mitos fundacionales, mesiánicos o de odio supremo. Lo que no advirtió fue que el actual Estado nación está fundado en algo tan artificial como lo es la convención. Le faltó añadir en su análisis que el Estado actual no sólo se mira como mito sino también como convención.

No hubiera sido posible completar el análisis que hace Cassier sobre el Estado sin los avances de Calasso que plantea una evolución de la legitimación pacífica. Para Calasso solo hay ciclos de sustitución de un régimen a otro: del rito al mito y del mito a la convención; del orden de la expiación al orden de las palabras y del orden de las palabras al orden de la artificialidad. La evolución de la mente humana se cumple tras la expulsión de un ciclo por otro donde la sangre es menos publicitaria, menos personalizada, pero no por ello se ha expulsado la violencia fundadora y conservadora. La ordalía de la legitimidad de la convención solo constituye un ciclo más de la evolución de las sustituciones realizadas por la psique humana para instaurar un orden.

Sin embargo, Calasso no dice nada acerca de la expulsión del régimen de la convención solo dice:

El paso del mundo del canon al de la convención se realiza con la sustitución del $<<$ límite sagrado>> por la <<barrera>>, como aclaraba Marx en los Grundrisse. Cambian un canon quiere decir cambiar un mundo. Cambiar una convención quiere decir, en el interior de ese mismo mundo, obtener resultados diversos. Y los resultados se confrontan en razón de su eficacia para el desarrollo. Violar el $<<$ límite sagrado >> quiere decir abandonar un orden que es social porque es el orden del mundo. Abatir una <<barrera >> quiere decir proponer un nuevo procedimiento. (Calasso, 2000: 223)

Calasso no se equivoca al decir que la convención como acuerdo arbitrario permite hacer funcionar todo tipo de mecanismo, desde el lenguaje hasta la sociedad, de modo que esta época de convenciones es consecuente con el mecanismo del capital y su proceso de 
desarrollo. Hasta ahora el capital ha derribado todas las barreras porque él mismo no se ha considerado como una barrera, cuando esto sea posible la tesis calassiana adquirirá su justo valor porque se comenzará a diseñar un nuevo procedimiento de validez de una nueva formación cultural que ha expulsado la norma de certeza del orden: libertad e inequivalencia en las relaciones sociales. Una paradoja que funciona como mecanismo social gracias a la eficacia de la convención.

Para concluir, entre la tesis calassiana de la barrera y la condición del conocimiento violento de la acción que se deduce de Benjamin, es decir entre una teoría de la sustitución y una filosofía de la historia media la experiencia del proceso de desarrollo del Estado nación que aún no ha terminado.

Sin embargo, estas dos propuestas teóricas son las que más definen una aproximación a la temporalidad del orden mundial establecido en estados nacionales porque estas teorías no se someten a las vicisitudes y contingencias de las prácticas diarias sino que diagnostican su resultado, en esto consiste su valor e importancia: que no importa hacia dónde se mueva el progreso en la cultura cuando se sabe de los resortes que la impulsan. 
Bibliografía.

AGAMBEN, Giorgio (1995). Homo sacer, Valencia, Pre-Textos.

BACHELARD, Gaston (2016). La poética del espacio, México, FCE. - (1978) La dialéctica de la duración, Barcelona, F.C.E.

BENJAMIN, Walter (1982). Para una crítica de la violencia, México, La nave de los locos.

CASSIER, Ernest (1974). El mito del estado, México, FEC. - (1985). Filosofía de las formas simbólicas, México, F.C.E.

CALASSO, Roberto (2000), La ruina de Kasch, Barcelona, Anagrama.

DERRIDA J. (1997). Fuerza de ley, Madrid, Tecnos.

DURAND, Gilbert, Las estructuras antropológicas del imaginario, Méx. F.C.E 204. -------------, La imaginación simbólica, tr. Marta Rojzma, Buenos Aires, Amorrortu, 2007.

HABERMAS, J. (1973). Problemas de legitimación en el capitalismo tardío, Madrid, Cátedra.

HORKHEIMER, Max, (2007). Crítica de la razón instrumental, La Plata, Terramar.

GELNER, E. (2001). Naciones y nacionalismo, Madrid, Alianza.

GIRARD, René (1995). La violencia y lo sagrado, Barcelona, Anagrama,

FINKIELKRAUT, A. (2000). La derrota del pensamiento, Barcelona, Anagrama.

JUNG, Carl (2001). El hombre y sus símbolos Méx., F.C.E.

KARATANI, Kojin (2003). Transcritique, London, Massachusetts Institute of Technology. (2010). "Revolución y repetición”, Theoria, Número 20, pp. 11-21.

KELSEN, Hans (1999). Logos, México, Fontamara

--------------- (2007). Teoría pura de derecho, Méx. Éxodo.

KOLAKOWSKY, Leszek (1973). Presencia del mito, Buenos Aires: Amorrourtu.

MARX, Karl (2007). Grundrisse, México, Siglo XXI, Vol. I.

---------- (2010). El capital, cap. VI inédito, México, Siglo XXI 
MAQUIAVELO, N (2009). El Principe, México, EUM.

ROUSSEUAU, J. (1990). Contrato social, México, Austral.

SCHMITT, Carl (1985). La dictadura, Madrid, Alianza.

SMITH, A (2001). Nacionalismo y modernidad, Barcelona, Istmo

TAFOYA, E (2012). La simbólica del buen salvaje, México, UNAM.

TAYLOR, Charles (1993). El multiculturalismo y la política del reconocimiento, Méx, F.C.E.

SUARTE, Alberto (2001). Permanencia del mito, México, Ed. Coyoacán. 